\title{
USE OF THE BEZIER CURVES FOR A VEHICLES DRIVING CYCLES MODELING
}

\author{
Valerii Dembitskyi \\ Department of Automobiles and Transport Technologies, Lutsk National Technical University, Lutsk, Ukraine \\ *E-mail of corresponding author: dvm2@meta.ua
}

\begin{abstract}
Resume
While performing the research of the vehicles operating characteristics in real operating conditions, a question of creation or correction of a movement driving cycle always appears. An absence of a mathematical model rather complicates the research process and makes a quick correction of movement conditions impossible. To solve the given problem, it was proposed to model a driving cycle using the Bezier curves. As a result of this research, it is stated that the most advantageous is to use the Bezier curves of the second and third degrees. During the analysis of results of driving cycles modeling and their comparison to the standardized and real movement cycles, a satisfactory coincidence of results was obtained. The conducted thematic research confirms the previous results, directed to creation of a universal dynamic model of a vehicle's driving cycle.
\end{abstract}

Available online: https://doi.org/10.26552/com.C.2021.1.B65-B75

\section{Article info}

Received 30 June 2020

Accepted 4 August 2020

Online 27 November 2020

\section{Keywords:}

driving cycle,

movement,

vehicle,

modeling,

Bezier curve,

coordinate

\section{Introduction}

In spite of an intensive development of vehicles with an electric drive, during their exploitation many questions, concerning an electric energy consumption by such vehicles in concrete operating conditions, appear. The mentioned question is particularly acute during the exploitation of commercial transport, namely the buses that run the city routes. Very often, there is a problem of considerable deviation of an electric energy consumption by the same vehicle in different operating conditions. Besides, the electric energy consumption, declared by the manufacturers, noticed in official documents, is usually rather lower than the real one. In addition, these differences do not allow unique evaluating of the electric drive vehicles exploitation efficiency. Appearance of such arguments and non-conformities is associated with the difference between the driving cycle applied during the test and the real operating conditions. In such a way, a question arises of creation of such a driving cycle that could be easily adapted to the necessary operating conditions. Its application should allow getting the real figures of electric energy consumption and evaluating efficiency of one or another vehicle. This problem is rather actual and the researches that are proposed to be made within the framework of a programme Horizon 2020, give evidence to this [1].

Analysis of the previously conducted researches, connected with the research and modeling of a driving cycle and concerning the energy consumption by vehicles according to driving cycles, testify to a great interest of scientists for solving the given problem. In the research work [2], the authors have investigated multi-factors model of movement and have made the corresponding experimental research with the aim to minimize the electric energy consumption, taking into account the concrete vehicles operating conditions. A driving cycle for a passenger car in Mashhad city, Iran, compared to the standard driving cycles in Europe and America, showed a significant distinction about the speed of movement [3].

A great number of the driving cycles, offered in literature, are corrected to the concrete operating conditions and do not allow to adapt them to the other conditions or to change the cycle parameters [4-10]. Besides a problem of creating a driving cycle for the concrete operating conditions and the movement modes, also appears a problem of changeability of a driving cycle in the same locality depending on the time of day [11].

The authors in a research work [12] have investigated different driving cycles that are used to find a consumption of fuel, electric energy and the levels of the vehicles exhaust gases emissions. All the investigated driving cycles have significant differences in time, movement speed and movement modes. Along with that, the authors draw attention to necessity of matching a driving cycle for concrete cities, regions.

A similar situation also occurs with the driving cycles for buses, besides it becomes complicated due to absence of a unique standardized cycle with help of which it would 


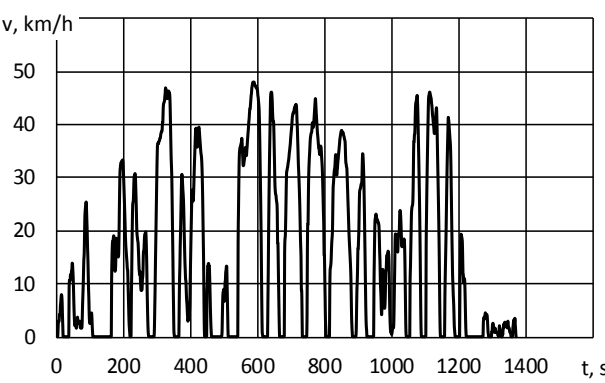

a)

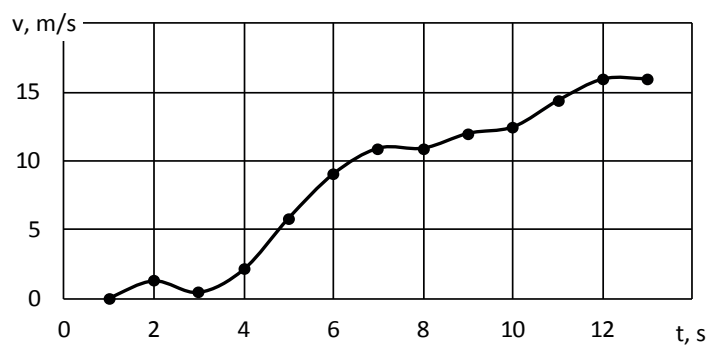

b)

Figure 1 Driving cycle of urban bus movement, obtained by experiment in Lutsk city (a); speed-up section (b)

Table 1 Equations of Bezier curves and level of validity of their approximation for a real vehicle movement cycle on the example of Lutsk city

\begin{tabular}{lcc}
\hline \multicolumn{1}{c}{ Bezier curve } & equation & validity level \\
\hline linear, $n=1$ & $V=1.3333 t-1.3333$ & 1 \\
quadratic, $n=2$ & $V=-0.0285 t^{2}+1.821 t-1.7689$ & 1 \\
cubic, $n=3$ & $V=-0.0031 t^{3}+0.0212 t^{2}+1.6207 t-1.9949$ & 0.9987 \\
quartic, $n=3$ & $V=-0.0033 t^{4}-0.1174 t^{3}+1.3298 t^{2}-3.5439 t+2.3598$ & 0.9966 \\
\hline
\end{tabular}

be possible to compare the research results. That is why many researches in separate cities and regions in order to determine a representative driving cycle were conducted [13-15]. A driving cycle is determined as a numeric series of speeds and a scheme of movement is reproduced by a number of parameters and operation characteristics [16].

\section{Research methods}

A problem of the driving cycles' creation is being solved for a long time. There are four main methods of the driving cycles' creation, namely: microtrip-based, segmentbased, pattern classification and modal cycle construction. Each of them has its own advantages and disadvantages and discerns by different complexity [17-19].

It is a common knowledge that a driving cycle in a graphic interpretation is a set of segments that include an acceleration of a vehicle, a movement with constant speed and braking (deceleration). The researches of real driving cycles, previously published [17, 20-24], are based on determination of extreme indices of the elementary sections of a cycle and of their deviation from standardized driving cycles.

A great problem today is still a possibility to build a driving cycle according to given data, the main of which can be the acceleration of speed-up and braking, the durability of every elementary section, the number of sections of speed-up, braking, acceleration. Results of analysis of the standardized and experimental driving cycles, described in literature sources, [20-24] demonstrate that any driving cycle can be shown as a set of curves that describe some of its section. It was proposed to take the Bezier curves as a base for building the driving cycles. The analysis of literature sources testifies about an effective usage of Bezier curves during the modeling of a vehicle mechanical trajectory [25-26], in the automatized vehicles control systems [27-28], modeling and prediction of the route of vehicle movement and avoidance of collision for pilotless vehicles [29].

\section{$3 \quad$ Research results}

During the creation of a driving cycle it is advantageous and the most optimal to use:

1) for modeling of constant movement sections - linear Bezier curves, at $n=1$,

$B(t)=(1-t) P_{0}+t P_{1}, t \in[0 ; 1]$,

where

$P_{0} \quad$ - position of the zero point,

$P_{1}$ - position of the finishing point,

$t$ - the time parameter.

2) for modeling of sections of speed-up and braking; - quadratic Bezier curves, at $n=2$,

$B(t)=(1-t)^{2} P_{0}+2 t(1-t) P_{1}+t^{2} P_{2}, t \in[0 ; 1]$,

where

$P_{0}$ - position of the zero point,

$P_{1}$ - position of the intermediate point,

$P_{2}$ - position of the finishing point.

- cubic Bezier curves, at $n=3$,

$$
\begin{aligned}
& B(t)=(1-t)^{3} P_{0}+3 t(1-t)^{2} P_{1}+ \\
& +3 t^{2}(1-t) P_{2}+t^{3} P_{3}, t \in[0 ; 1],
\end{aligned}
$$

where

$P_{0} \quad$ - position of the zero point,

$P_{1}, P_{2}$ - position of the intermediate points, 


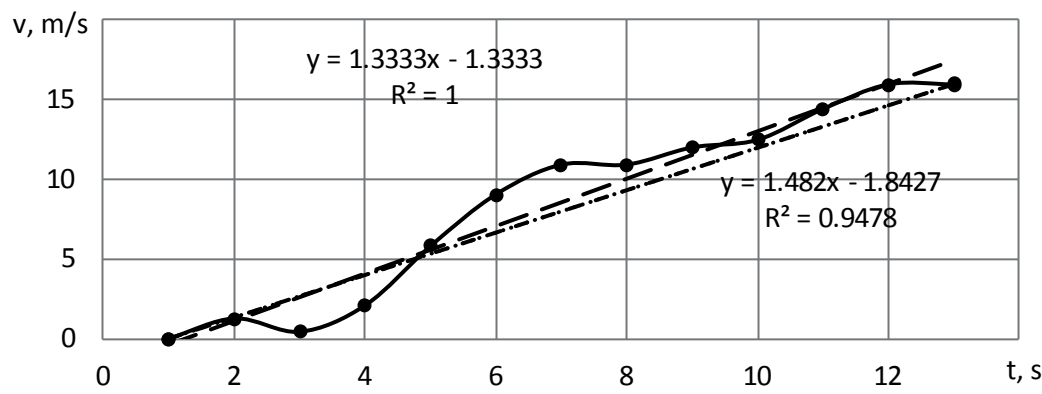

$\longrightarrow$ The experimental curve

- - Bezier curve

- The trend line for the experimental curve

........ The trend line for the experimental curve

a) The linear Bezier curve

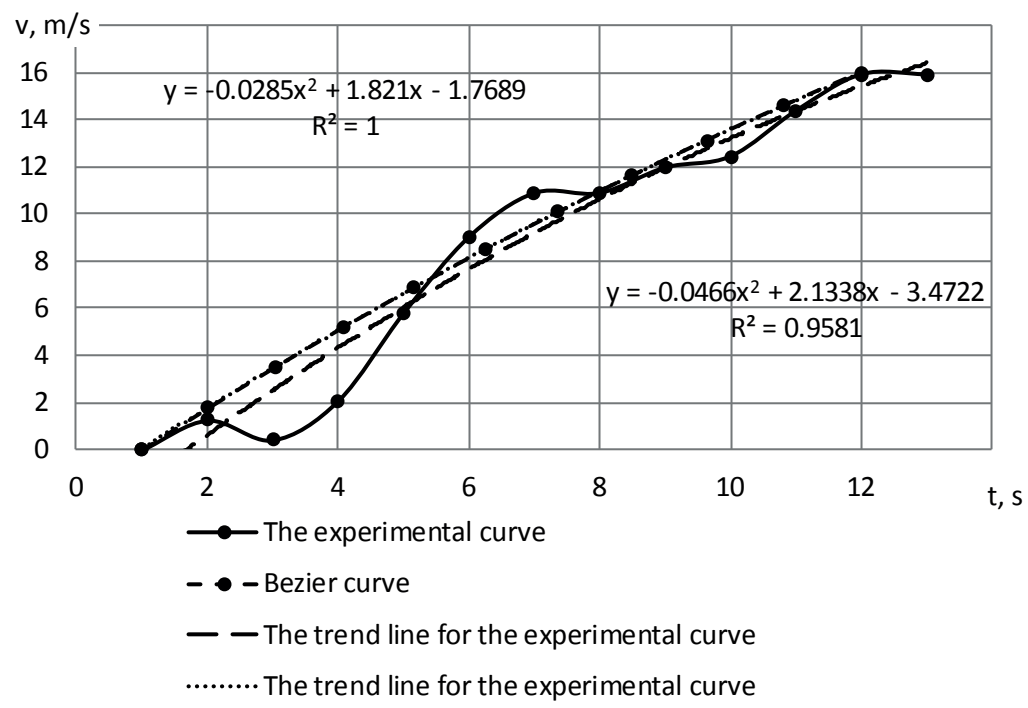

b) The quadratic Bezier curve

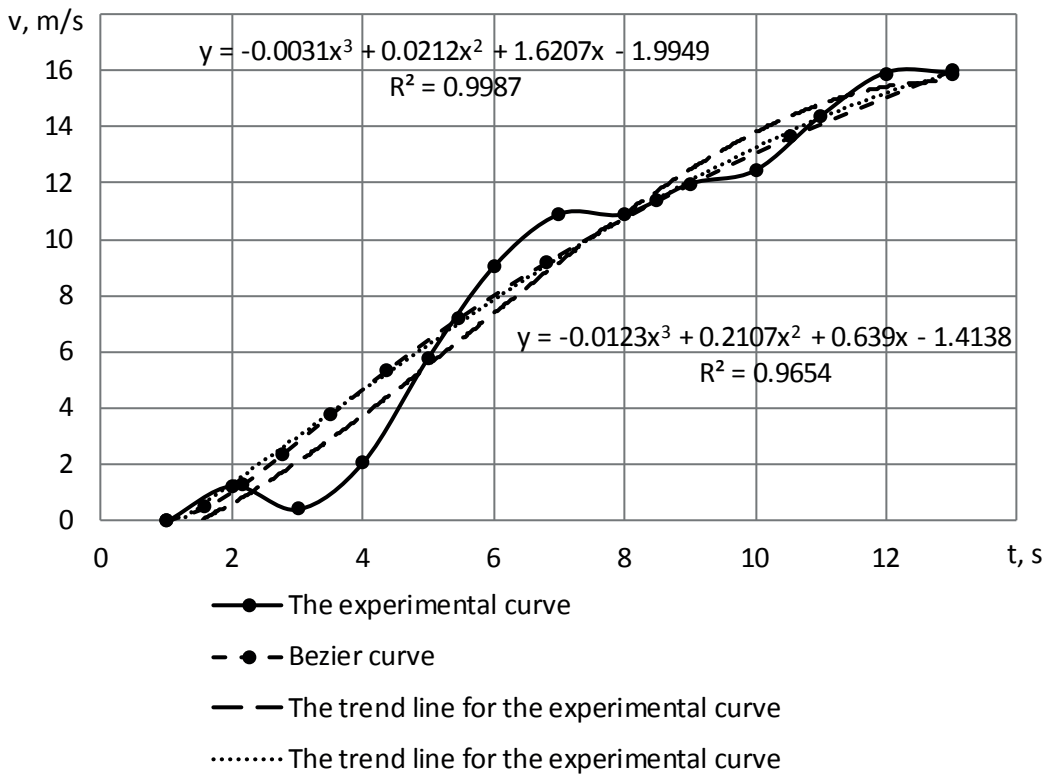

c) The cubic Bezier curve 


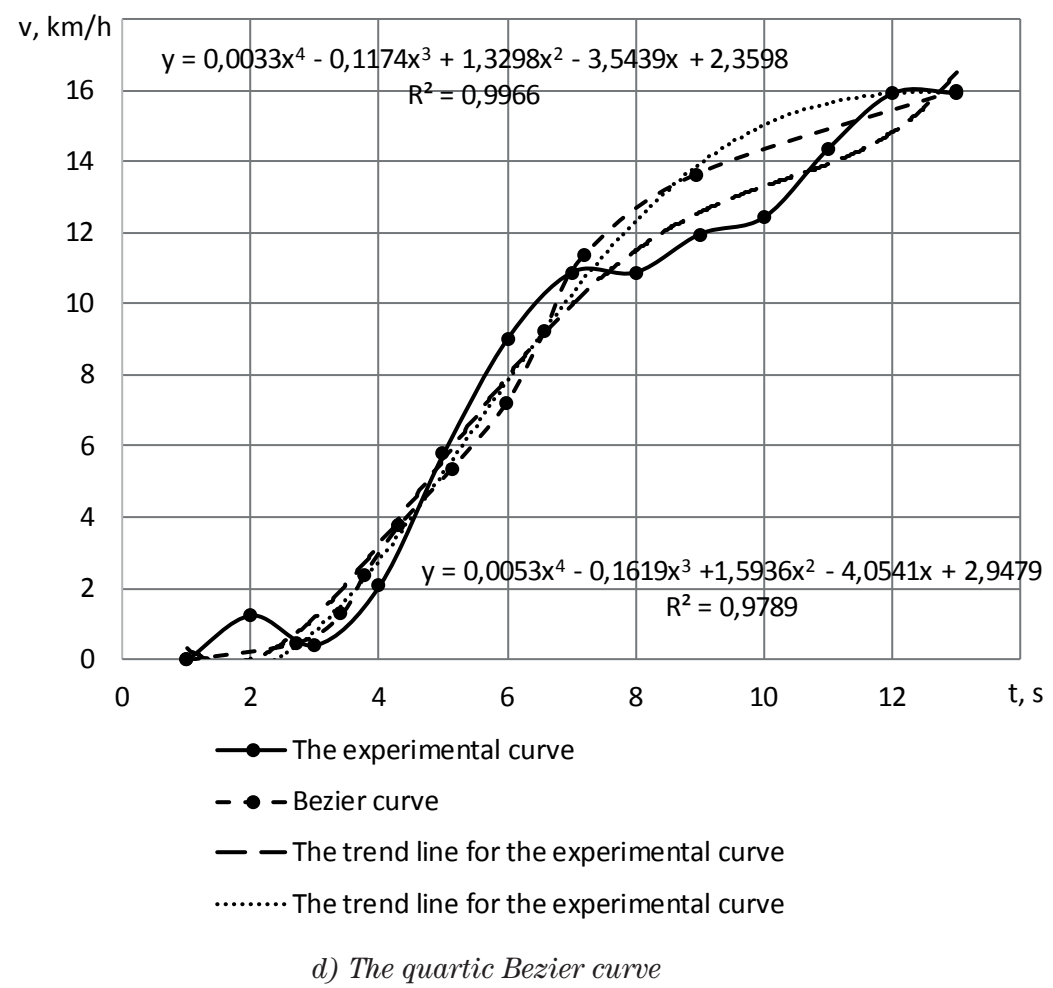

Figure 2 Results of the driving cycle speed-up section modeling

Table 2 Equations of a real driving cycle and a level of validity of their approximation

\begin{tabular}{ccc}
\hline Bezier curve & equation & validity level \\
\hline linear approximation & $V=1.482 t-1.8427$ & 0.9478 \\
polynomial curve of second degree & $V=-0.0466 t^{2}+2.1338 t-3.4722$ & 0.9581 \\
polynomial curve of third degree & $V=-0.0123 t^{3}+0.2107 t^{2}+0.639 t-1.4138$ & 0.9654 \\
polynomial curve of fourth degree & $V=-0.0053 t^{4}-0.1619 t^{3}+1.5936 t^{2}-4.0541 t+2.9479$ & 0.9789 \\
\hline
\end{tabular}

$P_{3} \quad$ - position of the finishing point.

- quartic Bezier curves, at $n=3$,

$$
\begin{aligned}
& B(t)=(1-t)^{3} P_{0}+3 t(1-t)^{2} P_{1}+3 t^{2}(1-t), \\
& \cdot P_{2}+4 t^{3}(1-t) P_{3}+t^{4} P_{4}, t \in[0 ; 1],
\end{aligned}
$$

where

$P_{0}$ - position of the zero point,

$P_{1}, P_{2}, P_{3}$ - position of the intermediate points,

$P_{4}$ - position of the finishing point.

A speed-up section, extracted from a driving cycle of urban bus movement, obtained by experiment in Lutsk city is shown in Figure 1.

While building the driving cycles, a speed is measured in $\mathrm{m} / \mathrm{s}$, because a change of speed by time is an acceleration. It was made with an aim to get the unique results. A vehicle speed on the graphs that demonstrate the driving cycles, is given in $\mathrm{km} / \mathrm{h}$, according to the common rules, including standards.

Using the Bezier curves of the first, second, third and fourth degrees, made a modeling of the speed-up section for an experimental driving cycle, shown at Figure 1. In Table 1 are given the appropriate equations and a level of validity of their approximation. The corresponding graphs are shown at Figures $2(a)$ to $(d)$.

In Table 2 there are shown the curves of approximation and the levels of validity for a real vehicle movement cycle graph on the example of Lutsk city.

To compare the obtained dependences, the appropriate calculations were conducted and their results are shown in Table 3. In the course of calculations, values of speeds were determined according to dependences shown in Tables 1 and 2. After that, the obtained data were compared to real speeds recorded directly during the movement.

The minimum deviation of speed, according to Table 3 , is seen in the course of using the Bezier curves of the second and third degrees.

As far as an average acceleration is concerned, another indicator of the driving cycle, analogical calculations were conducted, as well, for values of average acceleration. Results are shown in Table 4.

In Tables 3 and 4 there are some inaccuracies that are caused by external influence of the environment and by the vehicle's operating conditions, for example: speed 
Table 3 Deviations of modeling results from their real driving cycle for speed

\begin{tabular}{|c|c|c|c|c|c|c|c|c|}
\hline \multirow{3}{*}{$\begin{array}{l}\text { real speed } \\
\qquad(\mathrm{m} / \mathrm{s})\end{array}$} & \multicolumn{8}{|c|}{ approximation } \\
\hline & \multicolumn{2}{|l|}{ linear } & \multicolumn{2}{|c|}{ curve of second degree } & \multicolumn{2}{|c|}{ curve of third degree } & \multicolumn{2}{|c|}{ curve of fourth degree } \\
\hline & $\begin{array}{c}\text { approximation } \\
\text { by real } \\
\text { dependence }\end{array}$ & $\begin{array}{l}\text { Bezier } \\
\text { curve }\end{array}$ & $\begin{array}{c}\text { approximation } \\
\text { by real } \\
\text { dependence }\end{array}$ & $\begin{array}{l}\text { Bezier } \\
\text { curve }\end{array}$ & $\begin{array}{c}\text { approximation } \\
\text { by real } \\
\text { dependence }\end{array}$ & $\begin{array}{l}\text { Bezier } \\
\text { curve }\end{array}$ & $\begin{array}{c}\text { approximation } \\
\text { by real } \\
\text { dependence }\end{array}$ & $\begin{array}{l}\text { Bezier } \\
\text { curve }\end{array}$ \\
\hline 0.00 & -1.84 & 1.33 & 3.47 & 1.77 & 1.41 & 1.99 & -2.95 & -4.47 \\
\hline 1.25 & -2.08 & 1.25 & 2.63 & 1.23 & 1.83 & 1.61 & 0.92 & 1.14 \\
\hline 0.42 & -4.39 & -0.92 & -0.19 & -1.34 & -0.19 & -0.89 & 0.41 & 1.04 \\
\hline 2.08 & -4.21 & -0.58 & -0.43 & -1.36 & 0.01 & -0.89 & 0.90 & 1.18 \\
\hline 5.80 & -1.97 & 1.80 & 1.48 & 0.74 & 2.08 & 1.17 & 2.58 & 2.27 \\
\hline 9.03 & -0.22 & 3.69 & 3.00 & 2.40 & 3.52 & 2.78 & 3.44 & 2.64 \\
\hline 10.88 & 0.15 & 4.22 & 3.23 & 2.75 & 3.53 & 3.06 & 2.99 & 2.03 \\
\hline 10.88 & -1.33 & 2.88 & 1.70 & 1.30 & 1.72 & 1.56 & 1.03 & 0.34 \\
\hline 11.96 & -1.74 & 2.63 & 1.34 & 0.98 & 1.07 & 1.22 & 0.64 & 0.62 \\
\hline 12.43 & -2.75 & 1.77 & 0.48 & 0.12 & 0.00 & 0.38 & 0.14 & 1.05 \\
\hline 14.36 & -2.30 & 2.36 & 1.16 & 0.77 & 0.62 & 1.13 & 1.50 & 3.29 \\
\hline 15.91 & -2.24 & 2.57 & 1.55 & 1.09 & 1.17 & 1.63 & 2.62 & 4.88 \\
\hline 15.91 & -3.72 & 1.24 & 0.48 & -0.07 & 0.57 & 0.76 & 1.99 & 3.74 \\
\hline
\end{tabular}

and direction of wind, road cutting in a plan, its roughness and vehicle suspension, driver's behaviour. Those factors sometimes have a great influence [30]. The least deviation of the vehicle's acceleration, according to Table 4 , is noticed during application of the Bezier curves of the second and third degrees.

In such a way it was determined that it would be optimal to use the Bezier curves of the second and third degrees, with the aim to model and build the movement driving cycle. Along with that, using of the Bezier curves of the first degree is advantageous on the sections of a cycle with constant speeds.

During the building of the Bezier curves of the second and third degrees that describe the movement driving cycle, the biggest problem was determination of the intermediate points' $P_{1}, P_{2}$, positions. At first, it is necessary to investigate a simpler version, namely searching of point $P_{1}$ positions for the quadratic curve. Since a point $P_{1}$ on intervals $\left[P_{0} ; P_{1}\right]$ characterizes the linear Bezier curves, its position would be the position of intersection of the corresponding lines. As the initial and final points of a vehicle movement process are known, so the equation of a line could be written out using a formula:

$\frac{t-t_{1}}{t_{2}-t_{1}}=\frac{v-v_{1}}{v_{2}-v_{1}}$

where

$t_{1}, t_{2}$ - time of the beginning and the end of movement correspondingly, $\mathrm{s}$, $v_{1}, v_{2}$ - initial and final vehicle speed, $\mathrm{m} / \mathrm{s}$.

From that dependence, equations for lines of the speed-up $v_{a}$ and braking $v_{b}$ were obtained:

$v_{a}=\frac{v_{2}\left(t-t_{1}\right)-v_{1}\left(t-t_{2}\right)}{\left(t_{1}-t_{2}\right)}$

$v_{b}=\frac{v_{4}\left(t-t_{3}\right)-v_{3}\left(t-t_{4}\right)}{\left(t_{3}-t_{4}\right)}$.

After the dependences 6 and 7 were compared, positions of lines' intersection point, which correspond to the positions of point $P_{1}$, were obtained as:

$$
\begin{aligned}
& \frac{t\left(v_{1}-v_{2}\right)+v_{2} t_{1}-v_{1} t_{2}}{\left(t_{1}-t_{2}\right)}= \\
& =\frac{t\left(v_{3}-v_{4}\right)+v_{4} t_{3}-v_{3} t_{4}}{\left(t_{3}-t_{4}\right)}, \\
& t_{P_{1}}=\frac{-v_{4} t_{1} t_{3}+v_{3} t_{1} t_{4}+v_{4} t_{2} t_{3}-v_{3} t_{2} t_{4}}{v_{2} t_{3}-v_{1} t_{3}-v_{2} t_{4}+v_{1} t_{4}-} . \\
& -v_{4} t_{1}+v_{3} t_{1}+v_{4} t_{2}-v_{3} t_{2}
\end{aligned}
$$

Position $v_{P_{1}}$ of a point $P_{1}$ is calculated by expression:

$$
v_{P_{1}}=\frac{t_{P_{1}}\left(v_{1}-v_{2}\right)+v_{2} t_{1}-v_{1} t_{2}}{\left(t_{1}-t_{2}\right)}
$$

or

$v_{P_{1}}=\frac{\left(\frac{v_{2} t_{1} t_{3}-v_{1} t_{2} t_{3}-v_{2} t_{1} t_{4}+v_{1} t_{2} t_{4}-v_{4} t_{1} t_{3}+v_{3} t_{1} t_{4}+v_{4} t_{2} t_{3}-v_{3} t_{2} t_{4}}{v_{2} t_{3}-v_{1} t_{3}-v_{2} t_{4}+v_{1} t_{4}-v_{4} t_{1}+v_{3} t_{1}+v_{4} t_{2}-v_{3} t_{2}}\right)\left(v_{1}-v_{2}\right)+v_{2} t_{1}-v_{1} t_{2}}{\left(t_{1}-t_{2}\right)}$, 
Table 4 Deviations of modeling results from their real driving cycle for acceleration

\begin{tabular}{|c|c|c|c|c|c|c|c|c|}
\hline \multirow{3}{*}{$\begin{array}{c}\text { real } \\
\text { acceleration } \\
\left(\mathrm{m} / \mathrm{s}^{2}\right)\end{array}$} & \multicolumn{8}{|c|}{ Approximation } \\
\hline & \multicolumn{2}{|c|}{ linear } & \multicolumn{2}{|c|}{ curve of second degree } & \multicolumn{2}{|c|}{ curve of third degree } & \multicolumn{2}{|c|}{ curve of fourth degree } \\
\hline & $\begin{array}{c}\text { approximation } \\
\text { by real } \\
\text { dependence }\end{array}$ & $\begin{array}{l}\text { Bezier } \\
\text { curve }\end{array}$ & $\begin{array}{c}\text { approximation } \\
\text { by real } \\
\text { dependence }\end{array}$ & $\begin{array}{l}\text { Bezier } \\
\text { curve }\end{array}$ & $\begin{array}{c}\text { approximation } \\
\text { by real } \\
\text { dependence }\end{array}$ & $\begin{array}{c}\text { Bezier } \\
\text { curve }\end{array}$ & $\begin{array}{c}\text { approximation } \\
\text { by real } \\
\text { dependence }\end{array}$ & $\begin{array}{l}\text { Bezier } \\
\text { curve }\end{array}$ \\
\hline 1.25 & -0.23 & -0.08 & -0.84 & -0.54 & 0.41 & 1.61 & 3.87 & 5.61 \\
\hline-0.83 & -2.32 & -2.17 & -2.83 & -2.57 & -2.02 & -2.14 & -0.51 & -0.11 \\
\hline 1.67 & 0.18 & 0.33 & -0.23 & -0.01 & 0.21 & -1.31 & 0.48 & 0.15 \\
\hline 3.72 & 2.24 & 2.39 & 1.91 & 2.10 & 2.06 & -0.91 & 1.68 & 1.09 \\
\hline 3.23 & 1.74 & 1.89 & 1.51 & 1.66 & 1.44 & -3.03 & 0.86 & 0.37 \\
\hline 1.86 & 0.37 & 0.52 & 0.23 & 0.35 & 0.02 & -5.97 & -0.44 & -0.61 \\
\hline 0.00 & -1.48 & -1.33 & -1.53 & -1.45 & -1.82 & -9.33 & -1.96 & -1.69 \\
\hline 1.08 & -0.40 & -0.26 & -0.36 & -0.32 & -0.64 & -9.66 & -0.40 & 0.28 \\
\hline 0.47 & -1.01 & -0.86 & -0.87 & -0.86 & -1.08 & -11.58 & -0.50 & 0.43 \\
\hline 1.93 & 0.45 & 0.60 & 0.68 & 0.65 & 0.62 & -11.30 & 1.35 & 2.25 \\
\hline 1.54 & 0.06 & 0.21 & 0.39 & 0.32 & 0.55 & -12.73 & 1.12 & 1.58 \\
\hline 0.00 & -1.48 & -1.33 & -1.06 & -1.17 & -0.60 & -15.15 & -0.63 & -1.14 \\
\hline \multicolumn{9}{|c|}{ average acceleration values, $\mathrm{m} / \mathrm{s}^{2}$} \\
\hline 1.32 & -0.16 & -0.01 & -0.25 & -0.16 & -0.07 & -0.11 & 0.41 & 0.91 \\
\hline \multicolumn{9}{|c|}{ average acceleration values, $\%$} \\
\hline 100 & -12.12 & -0.76 & -18.94 & -12.12 & -5.30 & -8.33 & 31.06 & 68.94 \\
\hline
\end{tabular}

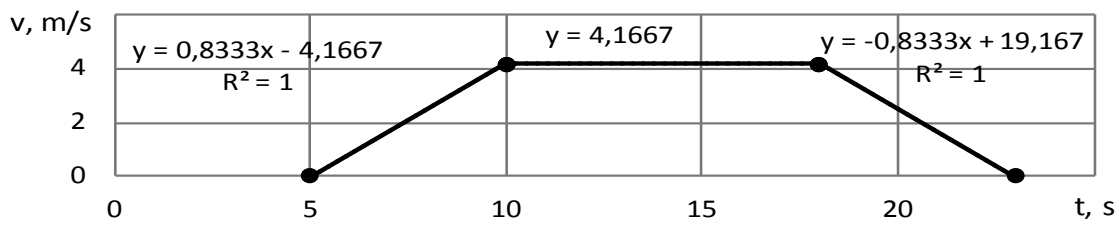

Figure 3 Elementary driving cycle

$v_{P_{1}}=\frac{2 v_{1}^{2} t_{2} t_{4}-2 v_{1}^{2} t_{2} t_{3}-v_{1} v_{4} t_{1} t_{3}+v_{1} v_{3} t_{1} t_{4}+v_{1} v_{4} t_{2} t_{3}-v_{1} v_{3} t_{2} t_{4}-2 v_{1} v_{2} t_{2} t_{4}+v_{2} v_{4} t_{1} t_{3}-v_{2} v_{3} t_{1} t_{4}}{\left(t_{1}-t_{2}\right)}-$

$-\frac{v_{P_{1}} v_{2} v_{4} t_{2} t_{3}+v_{2} v_{3} t_{2} t_{4}-v_{2} v_{4} t_{1}^{2}+v_{2} v_{3} t_{1}^{2}+v_{2} v_{4} t_{1} t_{2}-v_{2} v_{3} t_{1} t_{2}-v_{1} v_{4} t_{1} t_{2}+v_{1} v_{3} t_{1} t_{2}+v_{1} v_{4} t_{2}^{2}-v_{1} v_{3} t_{2}^{2}}{\left(t_{1}-t_{2}\right)}$.

Equations (9) and (12) give a possibility to find the positions of an intermediate point $P_{1}$ to build a Bezier curve.

If one builds a driving cycle with help of lines, so in a line equation $v=a t+b$, the angular coefficient $a$ stands for a value of average deceleration on a given segment of a driving cycle. This regularity should be taken into consideration during the building of driving cycles with the help of Bezier curves. Thus, a graph of a section «speed-up - braking», for a standardized driving cycle, shown in [31] (Figure 3) is obtained.

Taking into consideration that in the real driving cycles the sections of movement with a constant speed are actually absent, modeling of a part of the driving cycle, shown in Figure 3, was performed with help of the Bezier curves of the second degree. Results are shown in Figure 4.

Deviations of speed of the modeled driving cycle from the standardized one are shown in Table 5.
The maximum deviation is observed in points of passage from the speed-up to a constant speed and from the constant speed to braking. Along with that, taking into account that in real conditions of movement, the passages from one mode to another are made smoothly without abrupt changes, the given non-conformity can be neglected.

\section{Discussion of results}

The Bezier curves that are used for the driving cycles modeling (Figure 4) does not completely represent the necessary characteristics of a driving cycle. That is why it is advisable to build a driving cycle by parts, marking out the sections of the speed-up, deceleration and constant speed, using the quadratic Bezier curve during that the whole process. According to the given 


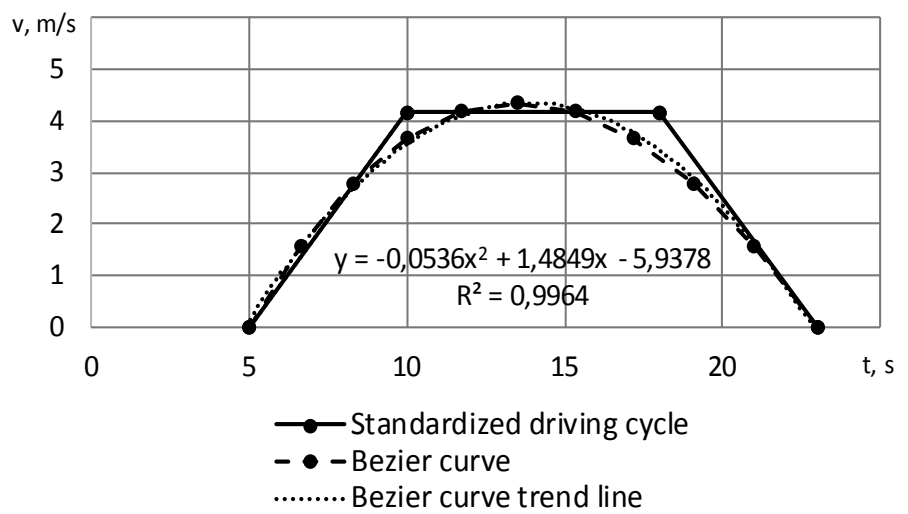

Figure 4 Elementary driving cycle

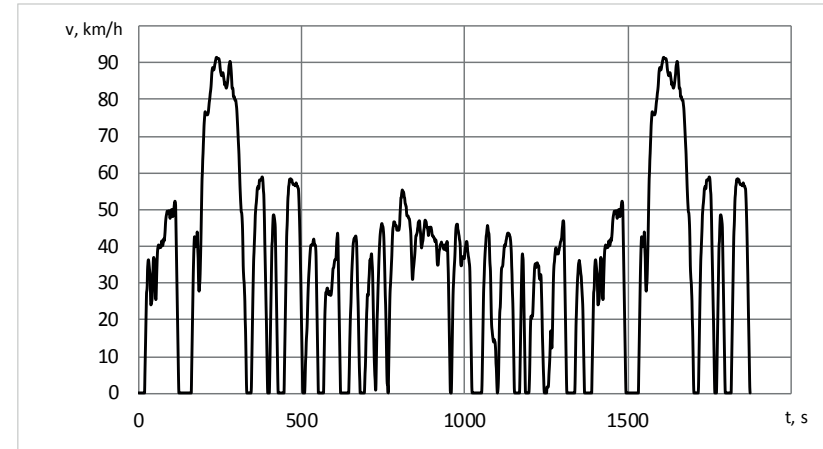

a)

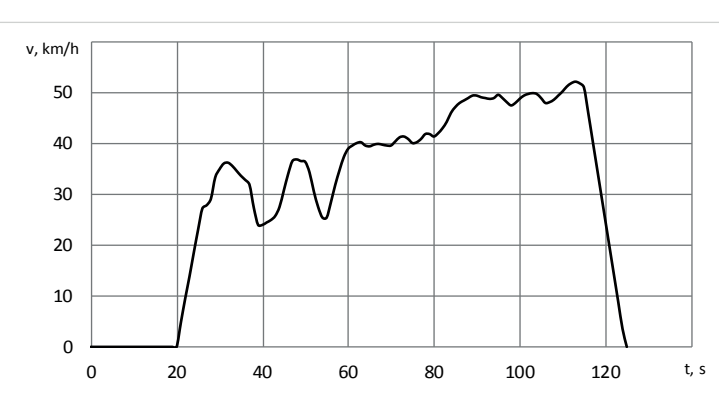

b)

Figure 5 Standardized driving cycle (a) and its section that was modeled using the Bezier curves (b)

Table 5 Deviations of the modeled driving cycle from the standardized one

\begin{tabular}{|c|c|c|c|c|}
\hline \multirow{2}{*}{ time, $\mathrm{s}$} & \multicolumn{2}{|c|}{ speed of driving cycle (m/s) } & \multicolumn{2}{|c|}{ deviations of a modeled driving cycle } \\
\hline & standardized & modeled & $\mathrm{m} / \mathrm{s}$ & $\mathrm{km} / \mathrm{h}$ \\
\hline 5 & 0.000035 & 0.1092 & -0.10925 & -0.3933 \\
\hline 6 & 0.83328 & 0.988 & -0.15472 & -0.55699 \\
\hline 7 & 1.66661 & 1.7566 & -0.08999 & -0.32396 \\
\hline 8 & 2.49994 & 2.415 & 0.08494 & 0.305784 \\
\hline 9 & 3.33327 & 2.9632 & 0.37007 & 1.332252 \\
\hline 10 & 4.1666 & 3.4012 & 0.7654 & 2.75544 \\
\hline 11 & 4.1666 & 3.729 & 0.4376 & 1.57536 \\
\hline 12 & 4.1666 & 3.9466 & 0.22 & 0.792 \\
\hline 13 & 4.1666 & 4.054 & 0.1126 & 0.40536 \\
\hline 14 & 4.1666 & 4.0512 & 0.1154 & 0.41544 \\
\hline 15 & 4.1666 & 3.9382 & 0.2284 & 0.82224 \\
\hline 16 & 4.1666 & 3.715 & 0.4516 & 1.62576 \\
\hline 17 & 4.1666 & 3.3816 & 0.785 & 2.826 \\
\hline 18 & 4.1676 & 2.938 & 1.2296 & 4.42656 \\
\hline 19 & 3.3343 & 2.3842 & 0.9501 & 3.42036 \\
\hline 20 & 2.501 & 1.7202 & 0.7808 & 2.81088 \\
\hline 21 & 1.6677 & 0.946 & 0.7217 & 2.59812 \\
\hline 22 & 0.8344 & 0.0616 & 0.7728 & 2.78208 \\
\hline 23 & 0.0011 & -0.933 & 0.9341 & 3.36276 \\
\hline
\end{tabular}




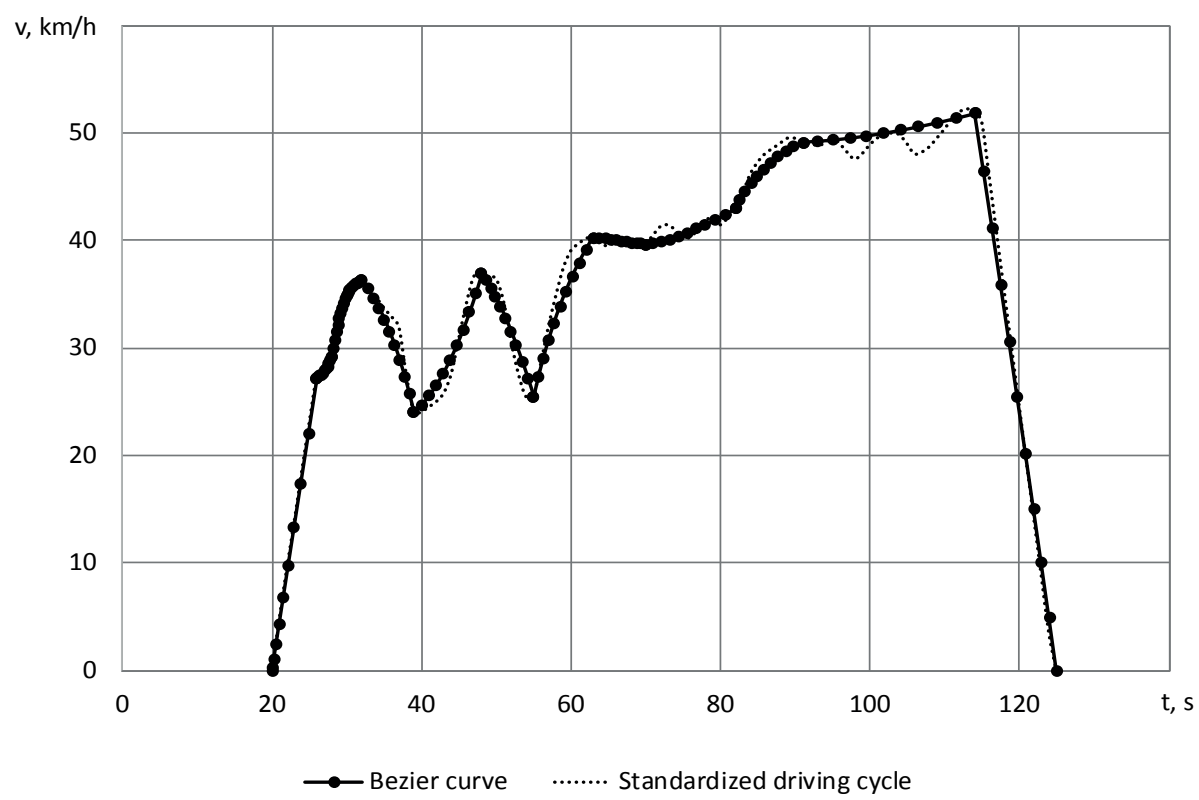

Figure 6 Modeling of the standardized driving cycle by Bezier curves

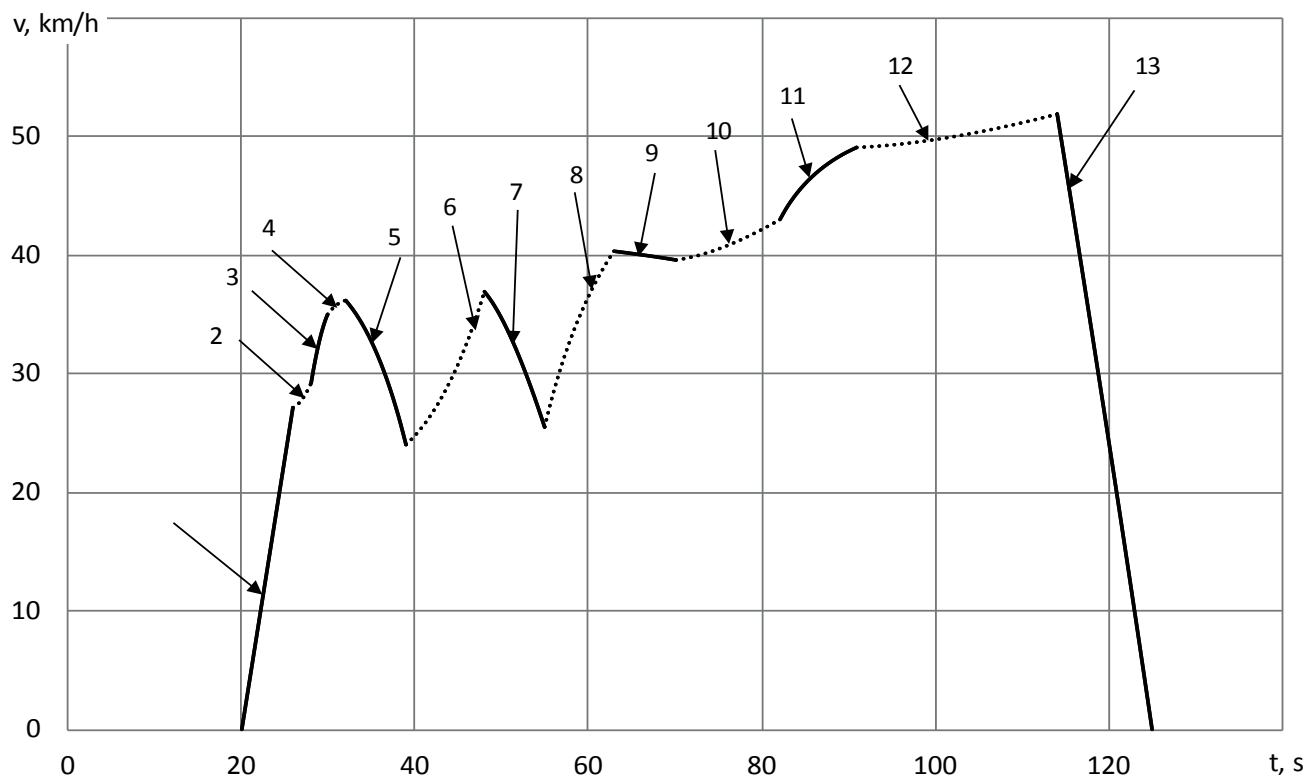

Figure 7 Elementary parts of the modeled driving cycle

method, a section of the driving cycle FTP was built, (Figures 5, 6).

While building a section of a driving cycle, for the initial point is taken a point of the vehicle movement beginning, while the final point, which at the same time is the initial point of the next section, has positions that correspond to the extreme value of speed (minimum and maximum).

During the modeling of a driving cycle, an FTP part was divided into 13 segments; each of them is in a model presented by the quadratic Bezier curve, shown in Figure 7. If in the quadratic Bezier curve the points $P_{1}$ and $P_{2}$ have the same positions, the Bezier curve of the second degree turns into a line. Some non-conformities of the modeled driving cycle with a standardized one can be eliminated by dividing these sections into smaller parts.

In Table 6 is given an extension for each part and the maximum speed deviation on a given part.

As a result of the research, the maximum deviation of speed between the standardized driving cycle and its model was found to be about $10 \%$ (elementary parts 5 and 12 ). Along with that, taking into consideration that a sign of speed's difference between the given driving cycles can be either positive or negative, an average deviation by a part of a cycle is about $3 \%$. To decrease the speed deviation o from the standardized driving cycle, a part 12 was additionally divided in three elementary parts (Figure 8). As a result of this, the maximum deviation for the elementary part 12 was 


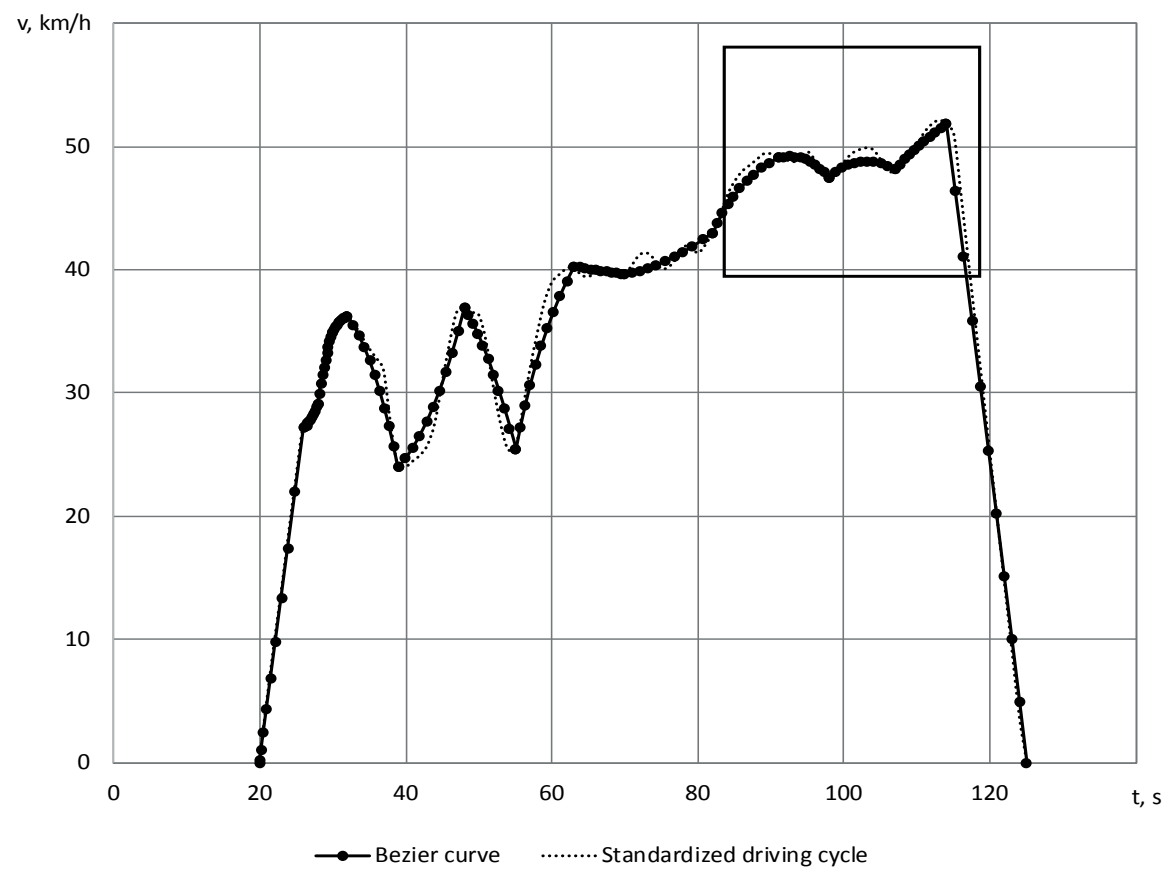

Figure 8 Division of a part of the $12^{\text {th }}$ driving cycle on the segments to get higher precision

Table 6 Extension for each part and the maximum speed deviation on an elementary part of the $12^{\text {th }}$ driving cycle

\begin{tabular}{ccc}
\hline $\begin{array}{c}\text { number of an elementary part of a } \\
\text { cycle }\end{array}$ & $\begin{array}{c}\text { extension of an elementary part of a } \\
\text { cycle (s) }\end{array}$ & \begin{tabular}{c} 
maximum deviation by speed (\%) \\
\hline 1
\end{tabular} \\
2 & 2 & 0.011 \\
3 & 2 & 1.926 \\
4 & 2 & 0.670 \\
5 & 7 & 9.629 \\
6 & 11 & 7.297 \\
7 & 7 & 4.475 \\
8 & 8 & 6.012 \\
9 & 7 & 1.464 \\
10 & 12 & 3.196 \\
11 & 9 & 2.603 \\
12 & 23 & 9.101 \\
13 & 11 & 0 \\
\hline
\end{tabular}

$2.2 \%$. In such a way, it was found that for increasing the length of an elementary part, the corresponding increasing of deviation is observed. A value of deviation would primarily depend on the length of an elementary part and a character of a curve on this part. As it was shown before, the polynomial curves of the second and third degrees gave the most accurate results.

An accuracy level, with the help of which a modeling was being made, should correspond to the accuracy level of the experimental research, i.e. the deviations of a modeled driving cycle should correspond to deviations that appear during the experimental research of vehicles using the given driving cycle.

\section{Conclusions}

The research objective was searching and investigation of possibilities for the vehicles driving cycles' modeling. To achieve this objective it was proposed to use the Bezier curves. The performed theoretic research has shown a possibility to realize the tasks of driving cycles' modeling using the mentioned curves. In addition to this, the optimal is to use the Bezier curves of the second degree and together with them - the linear Bezier curves.

A character of a proposed method of the driving cycle's modeling is a possibility to choose the desirable accuracy of the model, while using different lengths. As a result of 
this research, the maximum and minimum differences of speed between the real driving cycle and a proposed model were determined, that amount to $10 \%$ and $3 \%$, respectively. It was also set that decreasing of elementary parts increases accuracy of the model. Dividing one part into three smaller parts decreased the difference between cycles from $10 \%$ to $2.2 \%$ of elementary driving cycle sections.
It is certain that this process of modeling is rather difficult and the higher is the accuracy, the more difficult would be to model, however, the created model would be rather dynamic and can be easily changed in a case of change of some external factors. The performed thematic research confirms the previous results, aimed at a creation of a universal dynamic model of vehicles' driving cycle.

\section{References}

[1] Reducing the environmental impact of hybrid light duty vehicles - European Commission [online] [accessed 2020-0215]. Available from: https://ec.europa.eu/info/funding-tenders

[2] BRAUN, A., RID, W. The influence of driving patterns on energy consumption in electric car driving and the role of regenerative braking. Transportation Research Procedia [online]. 2017, 22, p. 174-182. ISSN 2352-1465. Available from: https://doi.org/10.1016/j.trpro.2017.03.024

[3] POURESMAEILI, M., F., AGHAYAN, I., TAGHIZADEH, S., A. Development of Mashhad driving cycle for passenger car to model vehicle exhaust emissions calibrated using on-board measurements. Sustainable Cities and Society, [online]. 2018, 36, p. 12-20. ISSN 2210-6707. Available from: https://doi.org/10.1016/j.scs.2017.09.034

[4] STEVES-BOOTH, A., MUNEER, T., KIRBY, H., KUBIE, J., HUNTER, J. The measurement of vehicular driving cycle within the city of Edinburgh. Transportation Research Part D. Transport and Environment [online]. 2001, 6(3), p. 209-220. ISSN 1361-9209. Available from: https://doi.org/10.1016/S1361-9209(00)00024-9

[5] LIN, J., NIEMEIER, D., A. Regional driving characteristics, regional driving cycles. Transportation Research Part D: Transport and Environment [online]. 2003, 8(5), p. 361-381. ISSN 1361-9209. Available from: https://doi.org/10.1016/ S1361-9209(03)00022-1

[6] HUNG W. T., TONG H. Y., LEE, C. P., HA, K., PAO, L. Y. Development of a practical driving cycle construction methodology: a case study in Hong Kong. Transportation Research Part D: Transport and Environment [online]. 2007, 12(2), p. 115-128. ISSN 1361-9209. Available from: https://doi.org/10.1016/j.trd.2007.01.002

[7] GUO, F., ZHANG, F. A study of driving cycle for electric cars on Beijing urban and suburban roads. In: IEEE International Conference on Power and Renewable Energy ICPRE: proceedings [online]. IEEE, 2016. p. 319-322. Available from: https://doi.org/10.1109/ICPRE.2016.7871224

[8] ANIDA, I. N., NORBAKYAH, J. S., ZULFADLI, M., NORAINIZA, M. H., SALISA, A. R. Driving cycle development of BAS KITe in Kuala Terengganu city to optimize the energy consumption and emissions. In: 1st International Postgraduate Conference on Mechanical Engineering IPCME 2018: proceedings [online]. IOP Conference Series: Materials Science and Engineering. 2019. Vol. 469. ISSN 1757-8981, eISSN 1757-899X. Available from: https://doi.org/10.1088/1757-899X/469/1/012112

[9] ARUN, N., H., MAHESH, S., RAMADURAI, G., NAGENDRA, S. Development of driving cycles for passenger cars and motorcycles in Chennai. Sustainable Cities and Society, [online]. 2017, 32, p. 508-512. ISSN 2210-6707. Available from: https://doi.org/10.1016/j.scs.2017.05.001

[10] CHEN, Z., ZHANG, Q., LU, J., BI, J. Optimization-based method to develop practical driving cycle for application in electric vehicle power management: a case study in Shenyang, China. Energy [online]. 186, 115766, ISSN 0360-5442. Available from: https://doi.org/10.1016/j.energy.2019.07.096

[11] YANG, Y., LI, T., ZHANG, T., YU, Q. Time dimension analysis: comparison of Nanjing local driving cycles in 2009 and 2017. Sustainable Cities and Society, [online]. 2020, 53, 101949. ISSN 2210-6707. Available from: https://doi.org/10.1016/j.scs.2019.101949

[12] ACHOUR, H., OLABI, A. G. Driving cycle developments and their impacts on energy consumption of transportation. Journal of Cleaner Production [online]. 2015, 112(2), p. 1778-1788. ISSN 0959-6526. Available from: https://doi.org/10.1016/j.jclepro.2015.08.007

[13] TONG, H., Y. Development of a driving cycle for a supercapacitor electric bus route in Hong Kong. Sustainable Cities and Society [online]. 2019, 48, 101588. ISSN 2210-6707. Available from: https://doi.org/10.1016/j.scs.2019.101588

[14] YUHUI, P., YUAN, Z., HUIBAO, Y. Development of a representative driving cycle for urban buses based on the K-means cluster method. Cluster Computing [online]. 2019, 22, p. 6871-6880. ISSN 1386-7857, eISSN 1573-7543. Available from: https://doi.org/10.1007/s10586-017-1673-y

[15] LAI, J., YU, L., SONG, G., GUO, P., CHEN, X. Development of city-specific driving cycles for transit buses based on VSP distributions: case of Beijing. Journal of Transportation Engineering [online]. 2013, 139. p. 749-757. ISSN 2473-2907, eISSN 2473-2893. Available from: https://doi.org/10.1061/(ASCE)TE.1943-5436.0000547

[16] HUERTAS, J., GIRALDO, M., QUIRAMA, L., DIAZ-RAMIREZ, J. Driving cycles based on fuel consumption. Energies [online]. 2018, 11(11), 3064. ISSN 1996-1073. Available from: https://doi.org/10.3390/en11113064 
[17] GALGAMUWA, U., PERERA, L. BANDARA, S. A Representative driving cycle for the southern expressway compared to existing driving cycles. Transportation in Developing Economies [online]. 2016, 2, 22. ISSN 2199-9287, eISSN 21999295. Available from: https://doi.org/10.1007/s40890-016-0027-4

[18] GALGAMUWA, U, PERERA, L, BANDARA, S. Developing a general methodology for driving cycle construction: comparison of various established driving cycles in the world to propose a general approach. Journal of Transportation Technologies [online]. 2015, 5(4), p. 191-203. ISSN 2160-0473, eISSN 2160-0481. Available from: https://doi.org/10.4236/ jtts.2015.54018

[19] KALT, S.; BRENNER, L.; LIENKAMP, M. Requirements for electric machine design based on operating points from real driving data in cities. World Electric Vehicle Journal [online]. 2019, 10(4), 60. eISSN 2032-6653. Available from: https://doi.org/10.3390/wevj10040060

[20] CHINDAMO, D., GADOLA, M. What is the most representative standard driving cycle to estimate diesel emissions of a light commercial vehicle? IFAC-PapersOnLine [online]. 2018, 51(5), p. 73-78. ISSN 2405-8963. Available from: https://doi.org/10.1016/j.ifacol.2018.06.213

[21] DREIER, D., SILVEIRA, S., KHATIWADA, D., FONSECA, K. V. O., NIEWEGLOWSKI, R., SCHEPANSKI, R. The influence of passenger load, driving cycle, fuel price and different types of buses on the cost of transport service in the BRT system in Curitiba. Transportation [online]. 2019, 46, p. 2195-2242. ISSN 0049-4488, eISSN 1572-9435. Available from: https://doi.org/10.1007/s11116-018-9925-0

[22] FOTOUHI, A., MONTAZERI-GH, M. Tehran driving cycle development using the k-means clustering method. Scientia Iranica [online]. 2013, 20(2), p. 286-293. ISSN 1026-3098. Available from: https://doi.org/10.1016/j.scient.2013.04.001

[23] GONG, H. M., GE, Y. S., WANG, J. F., YIN, H. Light-duty vehicle emissions control: a brief introduction to the China 6 emissions standard. Johnson Matthey Technology Review [online]. 2017, 61(4), p. 269-278. ISSN 2056-5135. Available from: https://doi.org/10.1595/205651317X696199

[24] WU, T., HAN, X., ZHENG M., OU, X., SUN, H., ZHANG, X. Impact factors of the real-world fuel consumption rate of light duty vehicles in China. Energy [online]. 2020, 190, 116388. ISSN 0360-5442. Available from: https://doi.org/10.1016/j. energy.2019.116388

[25] LATTARULO, R., GONZALEZ, L., MARTI, E., MATUTE-PEASPAN, J., MARCANO, M., PEREZ, J. Urban motion planning framework based on N-Bezier curves considering comfort and safety. Journal of Advanced Transportation [online]. 2018, 6060924, p. 1-13. ISSN 0197-6729, eISSN 2042-3195. Available from: https://doi.org/10.1155/2018/6060924

[26] THARWAT, A., ELHOSENY, M., HASSANIEN, A. E., et al. Intelligent Bezier curve-based path planning model using chaotic particle swarm optimization algorithm. Cluster Computing [online]. 2019, 22, p. 4745-4766. ISSN 1386-7857, eISSN 1573-7543. Available from: https://doi.org/10.1007/s10586-018-2360-3

[27] LATTARUlO, R., MARTI, E., MARCANO, M., MATUTE-PEASPAN, J., PEREZ, J. A speed planner approach based on Bezier curves using vehicle dynamic constrains and passengers comfort. In: 2018 IEEE International Symposium on Circuits and Systems ISCAS: proceedings [online]. IEEE, 2018. eISSN 2379-447X, p. 1-5. Available from: https://doi. org/10.1109/ISCAS.2018.8351307

[28] LATIP, A., BADARIYAH, N., ROSLI, O. Feasible path generation using Bezier curves for car-like vehicle. In: International Research and Innovation Summit IRIS2017: proceedings [online]. IOP Conference Series: Materials Science and Engineering. 2017. Vol. 226. ISSN 1757-8981, eISSN 1757-899X, 012133. Available from: https://doi.org/10.1088/1757899X/226/1/012133

[29] ABDELAAL, M, SCHON, S. Predictive path following and collision avoidance of autonomous connected vehicles. Algorithms [online]. 2020; 13(3), 52. eISSN 1999-4893. Available from: https://doi.org/10.3390/a13030052

[30] DEMBITSKYI, V., SITOVSKYI, O., PAVLIUK, V. Influence of a system "vehicle - driver - road - environment" on the energy efficiency of the vehicles with electric drive. In: 1st International Scientific Conference ICCPT 2019: Current Problems of Transport: proceedings. SciView. 2019. p. 162-173.

[31] EN 1987-1 Electrically propelled road vehicles - specific requirements for safety - part 1: On board energy storage. 